\title{
Sin límites entre el ángel y el monstruo: Naná y Sabine en la novela de Émile Zola
}

\author{
Julia MARTínEZ GONZÁLEZ \\ Universidad de Ankara (Turquía) \\ Departamento de Lengua y Literatura Españolas \\ martinez@ankara.edu.tr
}

Recibido: $24 / 02 / 2014$

Aceptado: 12/04/2014

\section{Resumen}

El ensayo analiza los personajes protagonistas femeninos en Naná, de Émile Zola, para demostrar que la categorización femenina es más complicada que una simple distinción entre ángel del hogar y mujer caída -dos de los términos más comunes para designar a la mujer en el siglo XIX-al producirse una inversión e incluso fusión de los personajes. En Naná se distinguen tres etapas: la primera de orden tradicional presentando al ángel del hogar (Sabine) frente al monstruo corrosivo (Naná); una segunda fase de confusión y desorden, donde las cualidades de ambas aparecen solapadas; y una tercera fase de restablecimiento del orden en el que Sabine vuelve a su papel de ángel del hogar mientras que Naná es castigada con la muerte. Aunque al final se restablece el orden social, salvaguardando la sociedad burguesa, existe un intento de resistencia a estos límites, abriendo un espacio alternativo de dualidad para la mujer.

Palabras clave: Naná, Émile Zola, mujer caída, ángel del hogar, siglo XIX, adulterio.

\section{Pas de limites entre l'ange et le monstre: Nana et Sabine dans le roman d'Émile Zola}

\section{Résumé}

L'essai analyse les personnages principaux féminins dans Nana, d'Émile Zola, pour démontrer que la catégorisation féminine est plus compliquée qu'une simple distinction entre l'ange de la maison et la femme déchue -deux des termes les plus communs pour désigner la femme au XIX ${ }^{\mathrm{e}}$ siècle-, quand se produit une inversion et même une fusion entre les deux personnages. Dans Nana on distingue trois étapes: la première, d'une manière traditionnelle qui présente l'ange de la maison (Sabine) face au monstre corrosif (Nana), une seconde phase de confusion et de désordre, où les qualités des deux apparaissent sournoisement, et une troisième phase de rétablissement de l'ordre où Sabine retrouve son rôle d'ange de la maison alors que Nana est punie par la mort; bien que la fin rétablisse l'ordre social, en sauvegardant la société bourgeoise, il existe une tentative de résistance à ces limites, ouvrant un espace alternatif de dualité pour la femme.

Mots clés: Nana, Émile Zola, femme déchue, l'ange de la maison, XIX ${ }^{\mathrm{e}}$ siècle, adultère. 


\title{
Questioning the Angel-Monster Dichotomy: Sabine and Nana
}

\author{
in Emile Zola's Novel
}

\begin{abstract}
This essay analyzes the two main female characters in the novel Nana by Emile Zola, with the aim to demonstrate that applying to women the nineteenth century categories of the "domestic angel" and the "fallen woman" is not that simple, since these characters may unexpectedly invert or even merge these categories. Three phases may be distinguished in Nana: the first one refers to the more traditional order that clearly differentiates the angel in the house (Sabine) and the corrosive monster (Nana); the second phase is more chaotic, since the qualities of both characters overlap; and finally, a third phase in which order is restored and Sabine becomes immersed again in her role as domestic angel, while Nana is deathly punished. Even though the social order gets restored, thus saving the morals of the bourgeois society, we witness an attempt to defy these conventional limits, a defiance that opens an alternative, more complex representation of women.
\end{abstract}

Key words: Nana, Emile Zola, fallen women, domestic angel, nineteenth century, adultery.

\section{Referencia normalizada}

Martínez González, J. (2014). "Sin límites entre el ángel y el monstruo: Naná y Sabine en la novela de Émile Zola". Thélème. Revista Complutense de Estudios Franceses, Vol. 29, Núm. 2: 375-390. http://dx.doi.org/10.5209/rev_THEL.2014.v29.n2.44155

Si hay mugeres bellas y famosas por sus atractivos, y por el número de sus amantes; también las hay más ilustres todavía, por su castidad, por el amor conyugal, y principalmente, por sus sentimientos maternos. Estas buenas mugeres debían servir de modelo a las demás, en aquellas ocasiones difíciles en que se pudiesen ver y encontrar.

Ruiz, R., (1742) Consideraciones Politicas sobre Conducta entre Marido y Muger (ix-x)

A partir del siglo XVIII empezaron a proliferar manuales de conducta para señoritas con el ánimo de inculcarles cualidades tan importantes para la época como la sumisión y la modestia, recalcando sin cesar que las mujeres, ante todo, debían ser angelicales. La cita con la que comencé el ensayo, y que pertenece a un manual de conducta dirigido a los esposos varones, apunta la cualidad esencial de ese don angelical femenino que reconforta al marido, la castidad, al mismo tiempo que resalta la misión ideal de la mujer de la época: limitarse al matrimonio, la maternidad y la domesticidad (Jagoe, 1998: 24). De acuerdo con esta cita, la castidad es lo que define a una esposa como ilustre frente a aquellas mujeres hermosas que han perdido esta cualidad tan preciada debido a su liberalidad sexual, un estado por otro lado impuro y deshonroso que hay que evitar a toda costa. Por ello se propone que, en el momento en que ambas se encuentren, sean las mujeres ilustres (castas y honradas) las que sirvan de modelo a las que no lo son mediante las cualidades angelicales de la castidad e inocencia. Después de 
todo, en aquella época se resaltaba enormemente la pureza de la mujer ya que según "la cosmovisión burguesa, ésta era naturalmente casta porque así se lo dictaba su falta de deseo erótico" (Jagoe, 1998: 32). Esta mentalidad, como bien explica Lawrence Rich, se fundaba en la idea de que "the middle-class / bourgeois woman was required to lack animal passion, and women's uncontrolled sexual desires were seen as a threat to both the biological and social evolution of race, one solution was to simply deny that these desires existed" (Rich, 2001: 513). Es este pensamiento el que explica el gran énfasis en salvaguardar la pureza y castidad en la mujer.

Lo que cabe preguntarnos es: ¿qué ocurre en realidad cuando una mujer considerada honesta se encuentra con la llamada devoradora de hombres? ¿Quién sirve de modelo a quién y qué ocurre con esos límites que la sociedad intenta implantar? ¿Existen en realidad unos límites tan estrictos? El presente estudio demostrará que no los hay y examinará la ruptura de estos límites entre el ángel de la casa -la considerada como esposa y madre ideal- y la loca o monstruo, o mujer caída -refiriéndonos a aquella mujer que no se rige por las normas de la sociedad y no se comporta como mujer ángel (Gilbert \& Gubar, 1979: 53). Es ésta última, la mujer caída, la que ha sido estigmatizada debido a sus transgresiones sociales al representar "the dangerous side in the dual image of women [...] she is the whore rather than the Madonna, the devil instead of the angel" (Starks, 1991: 105). Lo que demostraremos a través del ensayo -partiendo de la idea que defiende que "the monster may not only be concealed behind the angel, she may actually turn out to reside within (or in the lower half) of the angel (Gilbert \& Gubar, 1979: 29)- es que no es posible establecer esos límites tan estrictos que se entendían en el siglo XIX sino que más bien se produce una dualidad inherente en la mujer, o al menos un intento.

Para conseguir nuestro propósito nos basaremos en dos personajes femeninos -Naná y Sabine- de la novela de Émile Zola titulada Naná. Estas dos mujeres, al comienzo de la obra, podrían ser consideradas dos caras de la misma moneda, correspondiendo a la concepción de la época de categorizar a la mujer exclusivamente en uno de los dos polos opuestos que comentábamos anteriormente: el ángel o el monstruo. Es más, al compartir el mismo hombre, el conde Muffat, se las podría definir simplemente a una como la esposa traicionada y, a la otra, como la amante y monstruo, al no ser viable la concepción alternativa de una superposición de estas categorías: "The wife and mother in one set of social circumstances should not, and cannot be, the mistress and lover in another" (Tanner, 1979: 13). Sin embargo, la relación entre los dos personajes es mucho más compleja pues, conforme avanza la novela, observamos que estas mujeres no son tan diferentes como aparentaban e incluso podríamos afirmar que llegan a fundirse la una en la otra en algunos momentos, mostrándonos la incapacidad de separar al ángel del monstruo como sería de esperar. Por otra parte y como comprobaremos, los intentos de comportarse mediante unos parámetros distintos a los que se les había asignado en la obra no van a obtener el éxito deseado, por lo que estos personajes femeninos regresarán a su estadio inicial, reestableciéndose de nuevo los límites con los que se solía definir a la mujer dentro de la sociedad: "Los personajes se cuestionan los modelos tradicionales de una feminidad y/o de una masculinidad [...] y de igual 
manera[...] se reproducen los imaginarios que una época vehiculiza de éstos, de manera particular cuando de mujeres se trata" (Cansigno, 2000: 271).

Según Tony Tanner, el objetivo ideal de la familia burguesa, en una sociedad burguesa, era el mantener la estructura que se había establecido para alimentar el mito que atribuye a la sociedad un estado perenne (Tanner, 1979: 97), es decir, sin cambios. Para ello, uno de sus recursos va a ser la literatura y mediante ésta, los autores del siglo XIX suelen castigar con un final trágico a aquellas mujeres que no se apegan a los valores tradicionales (Cansigno, 2000: 271, nota 5). En la novela de Zola vamos a ser testigos de este hecho, pues los dos personajes femeninos, Naná y Sabine, serán castigadas por no ajustarse a estos valores impuestos por la sociedad patriarcal. El propio Émile Zola, comenta Francisco Caudet en su introducción, afirmaba en L'Ebauche: "Una sociedad se derrumba cuando la mujer casada le hace la competencia a una puta, y cuando Muffat deja que su mujer [Sabine] le deshonre mientras se deshonra a sí mismo con Naná" (Zola, 1988: 316). Zola presenta su triángulo amoroso -uno de los muchos que encontramos en la novela- compuesto por el conde Muffat, su esposa, la condesa Sabine, y Naná, la amante del conde. Mediante esta cita, el autor establece las normas por las que debe regirse la mujer para que una sociedad burguesa funcione, es decir, cada una debe permanecer en su lugar, sobre todo la mujer casada, quien en ningún caso debe intentar emular ni competir con el monstruo representado por la prostituta. En este ensayo examinaremos con profundidad las relaciones que se establecen entre los tres personajes mencionados, sobre todo entre Naná y Sabine que, como veremos, van a ser más similares de lo que incluso ellas mismas pensarían, contribuyendo con ello a ese derrumbe de la sociedad que citaba Zola.

Naná se va a caracterizar desde el principio por su gran erotismo, algo que va a arrollar y destruir a los hombres con los que se encuentra, quienes a su lado se vuelven indefensos y se dejan tratar como si fueran marionetas: no hay nada que Naná no consiga de ellos. Entre estas marionetas se encuentra el conde Muffat, quien según Kathryn Slott se convierte en "the vehicle for conveying the most intense, uncontrolled male reactions to Naná" (Slott, 1985: 102). En realidad podríamos definir a Naná como una fuerza pura de la naturaleza, misteriosa, incontrolable (Starks, 1991: 105) y por tanto sin límites dentro de la sociedad. Por su profesión de mala actriz y prostituta, se margina a Naná fuera de la sociedad honesta y se la encasilla en lo que se consideraba “a fallen woman" en el siglo XIX (Lowe, 1992: 96). Es más, según Brian Nelson, Naná es una fuerza diabólica y su papel es "a diabolic incarnation of the Fatal Woman" (Slott, 1985: 94).

Por otro lado, se nos presenta a Sabine, una condesa casada con el conde Muffat durante diecisiete años y a la que el matrimonio no le ha brindado lo que ella esperaba: "otros la compadecían, recordando su alegre risa, sus grandes ojos de fuego, antes que la encerrasen en aquel viejo palacio"" (Zola, 1988: 141). Según la

${ }^{1}$ Zola, Émile. Naná. Edición de Francisco Caudet. Madrid: Cátedra, 1988. Todas las citas del Naná pertenecen a esta edición, por lo que en adelante referiré sólo la página. 
propuesta de Schierse Leonard, podríamos considerar que Sabine se ajusta perfectamente a la categoría de Cage Bird, es decir,

[...] caught in society's and her family's views of how a good wife or nice girl or good mother should behave. To the external eye, these women may seem happy in the secure roles; confident, socially successful, adored and even idolized by their husbands and friends and lover [...] but their inner self-esteem and dignity is frequently shaky, for they usually realize, if unconsciously, that their worth in the role they have chosen depends entirely on the projections of their men rather than on their own nature or independently formed identity (Schierse Leonard, 1993: 108)

Esta es exactamente la forma en que el personaje de Sabine va a evolucionar en la novela, ya que la condesa va a refugiarse en la infidelidad como una válvula de escape a una vida de frustraciones. En un principio, no hay indicios que hagan pensar que Sabine no es feliz con su vida: es una condesa que vive en uno de los mejores barrios de París, una buena ama de casa, casada con un hombre a quien se llega a describir como "la virtud en persona" (224), con su hija Estelle, a quien logran colocar o casar. Sabine es incluso envidiada e idolatrada por sus amigas: " Vaya! Ya quisiera yo tener un salón como el tuyo! Al menos puedes recibir [...] ¡Quién estuviera en tu lugar!" (137). Sabine también es descrita en varias ocasiones como mujer honesta y casta, completando así la descripción de un verdadero ángel del hogar: "lleva una vida de claustro" (140), "frialdad de beata" (141), "juraba que era una mujer honradísima" (159). Sin embargo, se va a producir una ruptura en esta vida supuestamente ideal basada en las necesidades del hombre. Tony Tanner comenta:

The figure of the wife ideally contains the biological female, the obedient daughter, the faithful mate, the responsible mother, and the believing Christian and harmonizes all the patterns that bestow upon these differing identities. But if the marriage starts to founder, then the different identities and roles fall apart or come into conflict [...] In one way or another the person [...] will be compelled to seek some mode of extrication from at least one of them (Tanner, 1979: 17).

En nuestro caso concreto, Sabine va a buscar una válvula de escape a su papel asfixiante de compañera fiel, primero en Fauchery y más tarde en otros amantes, formando de este modo parte del mundo sin ataduras al que pertenece Naná.

Como observaremos, Sabine y Naná tienen más cosas en común de las que en un principio aparentan y estas similitudes van a reforzarse conforme avanza la novela. Esta evolución está íntimamente relacionada con la división que establece Romana Lowe de la novela Naná en tres etapas: una primera etapa de orden, en la que los personajes masculinos quedan separados de los femeninos y a éstos se les asignan los estereotipos de la época; una segunda etapa, en la que los límites se rompen y los aspectos tradicionales se ponen en entredicho; y una tercera etapa de reordenamiento, en la que un eje central reinstaura el orden original (Lowe, 1992: 95). Del mismo modo, vamos a experimentar estas tres etapas en los personajes de Sabine y Naná: una primera etapa en la que se contrastan los dos personajes por sus caracterizaciones de ángel frente a monstruo; una segunda etapa en la que estos límites no están tan claros; y una tercera etapa en la que tras la confusión se restablece el orden tradicional del que parte la novela. 
En la primera etapa de orden y, por tanto, contraste en los personajes de Sabine y Naná para preservar ese orden, es fundamental destacar las escenas en las que se describen las dos reuniones en sus respectivas casas y que marcarán, tal y como Francisco Caudet afirma en su introducción, las diferencias sociales entre sus moradores y anunciarán los efectos devastadores que causará Naná en el matrimonio Muffat (Zola, 1988: 43). La primera reunión que se presenta tiene lugar en casa de los Muffat, un palacete ubicado en el barrio del Roule, cerca del Ministerio del Interior y no lejos del palacio de Elíseo. Ya el lugar de la residencia familiar nos deja entrever que se trata de una familia de buena posición social y económica -condes- respetados por el resto de la sociedad burguesa. Es importante la descripción del salón en la que tiene lugar la reunión, no sólo como contraste con la casa de Naná, sino como contraste con los cambios de redecoración, por decisión de Sabine, que sufre el salón al final de la novela: "Nunca penetraba allí el sol; de día, una claridad verdosa iluminaba apenas la estancia; y por la noche [...] se subrayaba su aspecto sombrío [...] Reinaban allí una dignidad glacial y unas costumbres antiguas, de una época ya pasada que exhalaba un hálito de devoción" (135-6). Mediante esta descripción conocemos el ambiente en que se mueve Sabine, quien se deja llevar por la resignación y pasividad propias y esperadas de su género femenino: "Un ademán perezoso completó su pensamiento. No sería ella quien cambiase su salón, después de haber vivido en él diecisiete años [...] Por ahora continuaría en el mismo estado en que su suegra quiso conservarlo en vida" (137). El lector es consciente de que el peso de las tradiciones y lo que se espera de ella en la sociedad están muy presentes en Sabine y han hecho mella en su forma de enfrentarse a la vida. Sin embargo, existe un detalle en el salón que podría simbolizar un ápice de resistencia a esos valores convencionales: una butaca acolchada de seda roja con una blandura de edredón que contrasta con el "sillón cuadrado de madera dura y tela resistente" (136) de su esposo. La butaca es descrita como "el único mueble moderno, un rasgo de capricho introducido en aquel ambiente de severidad, y que chocaba" (136). Además, esta butaca parece un lugar en el que Sabine se siente protegida, como inferimos de una de sus reacciones durante la conversación sobre una señorita de sociedad que iba a entrar a religiosa: "Sí, es un trance terrible -murmuró la condesa, con un ligero escalofrío, arrellanándose más en el fondo de su butaca" (147-8).

Existen otros elementos en la fiesta de Sabine que más tarde contrastarán con los encontrados en la casa de Naná. Por ejemplo, los temas de conversación de los contertulios van a recaer sobre temas candentes de la actualidad: los huéspedes destacados que visitan la Exposición Universal, el rey y el emperador de Prusia, Bismark, de la toma del velo de una señorita de sociedad, etc. A pesar de estos temas formales, habrá uno del que los hombres hablen a espaldas de las mujeres y que les interesa mucho más: Naná y su fiesta para el día siguiente. En realidad los invitados a ambas fiestas son los mismos hombres, aunque sí difieren las mujeres que los acompañan, en las que encontramos un comportamiento mucho más correcto, de acuerdo a su posición social, que destaca por su discreción y falta de escándalo: "Las señoras discutieron. Pero sus voces eran muy discretas, y sólo de 
vez en cuando alguna risita quebraba la brevedad de su conversación" (148). El comportamiento de Sabine corresponde con su condición de dama de sociedad, como refleja su intento de controlar una risa escandalosa nada apropiada para la clase alta: "Y se echó a reír [Leónide][...] Sabine, contagiada por esa hilaridad, se llevó el pañuelo a los labios" (149).

Durante la reunión, destaca lo buena anfitriona y ama de casa que es Sabine, pues domina perfectamente todos los detalles clave para que la reunión sea un éxito. Para empezar, invita a un número limitado de personas, sólo a los íntimos, para que puedan estar más cómodos: "La condesa, auxiliada por su hija, servía el té. Como apenas habían venido más que los íntimos, las tazas y los platos de pastelillos circulaban familiarmente. Ni siquiera se levantaban las damas de sus sitios" (155). Sabine es descrita como una anfitriona de excelentes dotes: "Y la condesa, sin apresurarse, iba de un invitado a otro, no insistiendo y quedándose parada unos instantes, mirando a los hombres con ademán de interrogación muda, sonriendo después y pasando a otro lado" (155). Los concurrentes se marchan a medianoche, dando por concluida una reunión que empezó a las diez. Todo bajo un aura de perfección y formalidad de la clase aristocrática.

Examinemos a continuación algunos aspectos importantes en la fiesta de Naná, para contrastarlos con los mencionados anteriormente en relación a Sabine. En primer lugar, la fiesta de Naná tiene lugar después de la medianoche y durará hasta más tarde del amanecer del día siguiente, con lo que no se trata de un ambiente formal sino relajado y algo libertino, en la que los invitados se emborracharán y se sentirán libres de sus inhibiciones debido al consumo de champán (a diferencia del té que se toma en casa de los Muffat). En esta fiesta, es un restaurante el que aporta todo lo necesario: la cena, la vajilla, la cristalería, la mantelería, las flores y hasta las sillas y los taburetes: "Naná no hubiese encontrado ni una docena de servilletas en sus armarios" (162). Por otro lado, el número de invitados no se limita solamente a los íntimos, como ocurría en la reunión de Sabine pues, aunque en su salón "cabían veinticinco cubiertos, estrechándose un poco" (162), no dejan de llegar invitados, incluso algunos a los que ella no conoce, que han sido invitados a través de otros invitados, produciéndose una situación grotesca: "Ya lo saben [...] colóquense donde quieran [...] Así es más divertido" (171). Se deja entrever que Naná no tiene nada bajo control. Por otro lado, las conversaciones de los contertulios coinciden con los de la fiesta de Sabine, ya que se habla sobre los mismos hechos pero centrándose en aspectos íntimos y asuntos de faldas. Como ya se comentó, los invitados varones son los mismos que acudieron a la reunión en casa de Sabine, difiriendo la identidad de las damas, y con ello su comportamiento y educación: "Por un momento pareció aquello el salón de los Muffat; sólo que las mujeres eran otras" (179). Las mujeres invitadas son conocidas de Naná, también malas actrices y prostitutas -más fallen women- cuyo comportamiento produce un estado de ansiedad en Naná, pues se desespera al darse cuenta de que su papel de ama de casa es todo un fracaso: "Le parecía no estar en su casa. Toda esta gente la había ignorado y aturdido [...] hablando en voz alta [...] Ella misma se olvidaba de su papel de ama de casa" (186). En realidad Naná pretende pasar por una dama al 
tratar de imitar el ambiente de formalidad que se respira en casas de la alta sociedad, como por ejemplo la de Sabine. Sin embargo, la situación se le escapa de las manos debido a que su naturaleza no puede aspirar a ser un ángel del hogar. En este sentido, ni siquiera como ama de casa resulta una buena actriz.

En esta primera etapa que establece los límites entre el ángel y el monstruo, se producen ciertas anticipaciones de la fusión o ruptura de los mismos en la segunda etapa. Un aspecto clave, aparte de la butaca de Sabine de seda roja -definida por Fauchery como "un ensayo, el principio de un deseo y de un goce" (147)- es la propia descripción física de Sabine. Fauchery, muy interesado en Sabine y, cuya sospecha de infidelidad en esta mujer provoca que se sienta atraído por ella "despertando de nuevo su vicio" (147) - comenta su impresión sobre la condesa: "[...]destacaba su fino perfil de morena rolliza, en que sólo los labios, algo gruesos, denunciaban una especie de sensualidad imperiosa" (141). Es más, su curiosidad le hace preguntar a su primo si la condesa ha tenido algún amante, a lo que La Faloise contesta: “¡Pues, no, no!... ¿Dónde crees estar? [...] pero no sé a ciencia cierta [...] si la condesa tiene amoríos, debe de ser muy lista, pues nadie habla de tal cosa" (141). Con estas palabras La Faloise amenaza la ruptura de los límites entre la mujer honrada y la mujer fatal ya que, por un lado, da a entender que Sabine no tiene nada que ver con las mujeres con las que se relaciona Fauchery -del tipo de Naná, es decir, sexualmente liberales- pero por otro lado es algo que tampoco puede asegurar. La curiosidad de Fauchery aumenta y continúa su observación:

[...] sus ojos aún conservaban un fuego juvenil [...] Pero un lunar que percibió en la mejilla izquierda de la condesa, cerca de la boca, le sorprendió: Naná tenía otro absolutamente idéntico. Era muy gracioso. En el lunar se rizaban algunos pelillos; sólo que, en Naná, esos pelos eran rubios y, en la otra, de un negro azabache. Pero, daba igual: esta mujer no tenía ningún amante (143).

Esta primera descripción del lunar es muy relevante, pues, a pesar de las semejanzas que Fauchery encuentra entre Sabine y Naná, se sigue estableciendo el límite entre las dos mujeres basado en la existencia o no de amantes en sus vidas. Sin embargo, la fusión entre Sabine y Naná va a evolucionar a unos niveles simbólicos más transgresores:

$\mathrm{Al}$ resplandor de la lumbre, los negros pelillos del lunar que tenía en la comisura de los labios parecían rubios. El mismísimo lunar de Naná: hasta su propio color el paralelo entre Naná y la condesa. Les encontraban un vago parecido en la barbilla y en la boca; pero los ojos no eran en absoluto semejantes. Además, Naná tenía un aire de buena chica, mientras que, la condesa, no sabía uno a qué atenerse: parecía una gata dormida, con las uñas escondidas [...] (159).

Con estas impresiones, la diferenciación entre ambas no está tan clara ni es tan precisa, no sólo porque a causa de la luz de la lumbre sus lunares parezcan idénticos sino porque se produce una inversión en sus personalidades: Naná, que es la mujer fatal, es a la que atribuye el aire de buena chica mientras que a Sabine, dama de sociedad e impecable, se la describe como "no sabía uno a qué atenerse", quebrándose los límites entre ambos personajes femeninos. Ya no parece tan obvio 
distinguir al ángel de la fuerza diabólica sino que más bien parecen fundirse. Este hecho será determinante para dar paso a la etapa de desorden en la novela.

En esta segunda etapa de desorden, los límites entre Sabine y Naná se rompen, dando lugar a una inversión en los personajes. Encontraremos a Naná, ya convertida en la amante del conde Muffat pero que sigue en su empeño de ejercer como mujer honrada. Por otra parte, Sabine, en su viaje a la casa de campo de una de sus amigas, se deja llevar por sus instintos y termina cayendo en brazos de Fauchery. Examinemos con cuidado lo que denominamos la naturaleza de estas dos mujeres.

Naná destaca en la novela por su sexualidad y erotismo, una característica que consigue que los hombres se rindan sumisamente a ella tanto emocionalmente como físicamente, y que incluso se arruinen para satisfacer su apetito voraz (Perry, 1991: 159). Todo su poder se origina en una cualidad que la hace totalmente seductiva y es lo que en la novela se define como "odeur de femme" (158). Este aspecto es fundamental, en contraste con Sabine, si tenemos en cuenta que de Sabine se duda incluso de si tiene muslos (159). Según Katrina Perry, lo que hace tan significante el olor de Naná es la cualidad de ser natural, lleno de vida y dador de vida, además de una manifestación de su condición social -como un afrodisíaco barato (Perry, 1991: 159). Por eso Sabine, perteneciente a la alta burguesía, carece de este tipo de aroma, al menos en apariencia. Este olor en Naná consigue que los hombres sientan una sensación de vértigo por la confusión a la que les embarga (Lowe, 1992: 106). Un claro ejemplo se refleja en la escena en la que el conde Muffat baja a los camerinos para visitar a Naná, y en la que somos testigos de su poder femenino atrayente cuyo olor opera, dentro la novela, como el medio de deseo entre la cortesana y sus amantes de la clase alta (Perry, 1991: 161). Muffat se siente mareado, "temiendo desfallecer por aquel olor a mujer" (215) y es este mismo olor el que va a despertar un fantasma dormido en la vida de Muffat: su enfrentamiento con lo desconocido, es decir, la mujer sexual (Perry, 1991: 161). Mediante esta sensación, recuerda su juventud y la frialdad que la rodeaba: "Cuando besaba a su madre, cada noche sentía, hasta en un sueño, el hielo de ese beso. Un día al pasar, había percibido, por una puerta entornada, a una doncella que se estaba lavando; y éste era el único recuerdo que le turbó, desde la pubertad al matrimonio" (223). Con estas reflexiones se nos informa sobre la gran influencia en su vida de la educación recibida por su madre y lo que se esperaba de él como hombre cristiano, completando así la información sobre él dada en la fiesta:

La mamá de Muffat [...] era una vieja insoportable, muy beatona, tenía un aire imponente y un gesto autoritario [...] era quien le había dado esta hermosa educación: confesión diaria, nada de escapadas, ningún devaneo juvenil. Cumplía con la iglesia y tenía crisis de fe de violencia sanguínea, parecidas a accesos de calenturas ardientes [...] Cuando se casó, aún no lo había catado (142).

\footnotetext{
${ }^{2}$ Según el Petit Robert, el término coloquial para prostituta ("puta"), deriva del latín "putidus", que significa "stinking" (Perry, 1991: 163).
} 
Y es que, tal y como apunta Cansigno, Zola aprovecha el relato de la vida de las mujeres para descubrir el mundo de los varones y sus fantasmas de lo femenino, es decir, el mundo de la perversión masculina así como su misoginia (Cansigno, 2000: 272). En el caso del conde Muffat, nos encontramos ante un joven inhibido por la autoridad materna, quien no ha tenido espacio para actuar libremente siguiendo sus instintos, para el que lo más parecido a una experiencia sexual serían las crisis de fe. Ahora, mediante el poder de Naná, todo su pensamiento va a dar un giro radical: "Era su juventud, que despertaba al fin, una glotona pubertad de adolescente, ardiendo de improviso en su frialdad de católico y su dignidad de hombre maduro" (240). Si analizamos el resto de sus reflexiones, podremos observar que su esposa Sabine también ha sido víctima de esta educación, pues el conde nunca la miró como mujer sino como un deber conyugal:

Había encontrado en su mujer una estricta obediencia a los deberes conyugales; él mismo sentía una especie de repugnancia devota. Crecía, envejecía, ignorando la carne, doblegado a rígidas prácticas religiosas $[\ldots]$ Y bruscamente, le arrojaban en este camerino de actriz, delante de aquella muchacha desnuda. Él, que nunca había visto a la condesa ponerse las ligas, asistía a los detalles íntimos del tocado de una mujer, con el jaleo de tarros [...] y en medio de aquel olor tan fuerte y agradable (223).

De nuevo, esta vez mediante la percepción de Muffat - un hombre burgués del siglo XIX- encontramos los límites entre Sabine ("obediencia a los deberes conyugales", a la que nunca había visto ponerse las medias) y Naná (una actriz, desnuda sin rubor, con un olor fuerte pero agradable). El conde nunca hubiese imaginado que su mujer pudiera ser descrita tal y como él hace con Naná: "Naná, confusamente, era para él el diablo, con sus risas, con su pecho y su grupa, henchidos de vicios" (223). Frente a la figura angelical, en un principio Sabine, Muffat contrasta esta naturaleza diabólica sin tener la más remota impresión de que Sabine comparte con Naná más características femeninas de las que aparenta.

Continuando en esta segunda etapa de desorden, o inversión en los personajes de Sabine y Naná, encontramos a la erótica Naná tratando de parecerse a una dama de sociedad. Entre sus intentos destaca la adquisición de una propiedad en el campo que le permite darse un respiro de sus amantes aunque, por otra parte, es en ese lugar donde tiene lugar su primer encuentro sexual con el conde Muffat: "Y se acostó con Muffat pero sin placer" (279). Asimismo es durante su estancia en el campo cuando sufre de unos ataques de buenos sentimientos con respecto a su hijo Louiset, de quien en realidad sólo se acuerda por temporadas: "[...] con ideas de educar religiosamente a Louiset y todo un plan de buena conducta para ella" (279). Todo en vano, porque se trata de simples impulsos de duración limitada. Por otro lado, cuando rompe su relación con Muffat y con Steiner, y con el resto de amantes, se propone una vida sencilla, pero honesta, con su amado Fontan. Durante este período Naná renuncia a su antigua vida de prostituta y se vuelve totalmente sumisa a este hombre al que ama (Lowe, 1992: 103). Hasta tal grado llega su sumisión que aguanta los abusos físicos y psicológicos de Fontan después de dos semanas de plena felicidad. Tras esta decepción, Naná vuelve al teatro y con él a su vida 
desordenada y de liberalidad sexual. No por ello se frena su deseo de ser honesta y obliga a Muffat a que interceda por ella para que le asignen un papel de mujer honrada en la nueva obra que preparan. Naná, cansada de interpretar papeles de cocotte, está totalmente convencida de que es ideal para ese papel de mujer honrada, a quien cree imitar a la perfección:

[...] retrocedió hasta la ventana, y enseguida volvió infatuada, midiendo sus pasos con aire circunspecto de gallina que teme ensuciarse las patas [...] Naná se paseó un instante, para mostrarse bien en todo su juego, con leves sonrisas, temblorcitos de párpado y balanceos de faldas y [...] dijo: “¿Qué tal? Se hace así, ¿no? (378).

Para Naná se trata de una pose, quizás porque para ella, el ser catalogada como mujer honrada depende más de las apariencias y del ensayo: "¡Cuando te digo que domino el papel de mujer honrada! He ensayado en mi casa; ninguna tiene mi airecillo de duquesa que se burla de los hombres [...] Ese aire se tiene en las venas [...] Y además, quiero hacer de mujer honrada; sueño con ello" (378). Al final Naná consigue el papel pero la obra resulta un desastre, como prueba de su doble fracaso como actriz y como mujer honrada frente a la sociedad. Sin embargo, Naná parece alcanzar un estadio intermedio - mitad ángel mitad diablo- pues sí que sufre una transformación en su naturaleza: "Lo prodigioso fue que esa robusta muchacha, tan torpe en la escena, tan chusca cuando quería hacer de mujer honrada, representaba a la maravilla fuera del teatro los papeles de dama encantadora, sin esfuerzo alguno" (391).

En el análisis de Sabine es fundamental su paso por la casa de campo, donde también acudirá su primer amante: Fauchery. Para explicar la influencia de la naturaleza en la consumación del adulterio de Sabine, es muy útil tener en cuenta algunas reflexiones de Jo Labanyi ${ }^{3}$, quien afirma que el adulterio es una metáfora de disolución de los valores, algo que ocurre cuando los límites entre lo social y lo natural se rompen. Es más, la estabilidad de la sociedad depende del mantenimiento de estos límites que separan la ciudad de lo natural (Labanyi, 1986: 54). De esta forma, el matrimonio establece la demarcación entre la actividad sexual aprobada por la sociedad y la actividad sexual salvaje - es decir, sin leyes- por lo que el adulterio es la intromisión de lo natural en la institución social del matrimonio. Según explica, la mujer antes del matrimonio se considera naturaleza, a través del matrimonio formaría parte de lo social, y el adulterio correspondería a la inclusión de la naturaleza en lo social (Labanyi, 1986: 56). Por eso la mayor parte de las escenas de adulterio tienen lugar en alguna zona cultivada, dentro de lo que sería denominado como ciudad, donde estos límites de lo que es natural y social se confunden (Labanyi, 1986: 55). Podemos aplicar todas estas nociones al caso de Sabine pues su llegada al campo tiene una gran influencia tanto en su actitud como en sus acciones: "Sabine, muy alegre, hablaba de sus recuerdos de juventud, que acababan de despertarse [...] no

\footnotetext{
${ }^{3}$ Estas reflexiones están basadas en el libro de Tony Tanner, Adultery in the Novel (1979) y en el artículo de Jo Labanyi "City, Country and Adultery in La Regenta" (1986).
} 
había visto a la condesa [...] la encontraba muy animada, con cierto cambio en la fisonomía" (242). Tan sólo con la llegada al campo y con esos recuerdos que la animan, que se refieren a su juventud antes del matrimonio, parece sentirse más alegre. Así como su esposo despierta a esa pubertad tardía mediante la naturaleza fatal de Naná, Sabine despierta a una nueva juventud llena de vida mediante su contacto con la naturaleza. Es más, relacionándolo con los comentarios tan interesantes de Jo Labanyi y Tony Tanner sobre el adulterio, y tal y como el conde nos informa después, parece que la relación amorosa entre Sabine y Fouchery comienza en plena naturaleza: "Una tarde había sorprendido a Sabine, bajo los árboles, tan conmovida que ni siquiera acertaba a contestarle" (305). Es curioso que, antes de que esta infidelidad llegue a boca de todos, es la misma Naná la que lo intuye nada más verse con ella:

Ya me lo sospechaba $[\ldots]$ por más condesa que sea, bien poco vale $[\ldots]$ Ya sabe que tengo buen ojo. En este momento conozco a esa condesa como si la hubiese parido [...] ¿Qué se apuesta a que engaña al conde con esa víbora de Fauchery? Les digo que se acuesta con él. Es cosa que las mujeres comprendemos al momento (271).

Esta vez es Naná la que rompe la demarcación entre el ángel y el monstruo. Según Muffat, Naná es "aquel monstruo desnudo, estúpido, asándose como una oca, destilando baba sobre todo lo que él respetaba desde hacía cuarenta años!" (304). Sin embargo, Naná es consciente de que no hay tanta diferencia entre ella y Sabine, a pesar de que ella no posea un título de condesa. En una de las peleas con Muffat, Naná encuentra las palabras adecuadas para defenderse de sus afrentas, sobre todo cuando se la acusa de no ser honrada: " $i L a s$ mujeres honradas se dedican a birlarnos nuestros queridos! [...] ¡Buenas están hechas, vuestras mujeres honradas!” (303); "Puta, ¿de qué? ¿Y tu mujer?" (315). Al final, es el propio conde el que accede a esa visión de su esposa, Sabine, como un reflejo de su propia infidelidad con Naná:

Mientras él se ponía en mangas de camisa en casa de una putilla, su mujer se desnudaba en la alcoba con su amante; nada más sencillo y más lógico [...] Perseguíanle abrasadores imágenes. Naná desnuda: bruscamente, evocó a Sabine desnuda. Al llegar a esta visión, que las reunía en un parentesco de impudicia, bajo un mismo aliento de deseo [...] (305).

Finalmente, se produce esta fusión de Sabine en Naná que habíamos anticipado en la primera etapa mediante la comparación de los lunares. Sabine no representa en esta etapa la figura de esposa y ángel de la casa ideal que encontrábamos, sino que, a ojos de la sociedad y de su marido, ha degenerado al mismo lugar que Naná: una mujer caída. Ésta sería tan sólo una primera fase de evolución en Sabine a la que, todo hay que decirlo, el adulterio parece sentarle muy bien: "Sabine, de vestido blanco, adornado de maravilloso encaje inglés, estaba triunfante de belleza, joven, alegre, con un asomo de embriaguez en su continua sonrisa" (485). Este cambio de ánimo también se refleja en la redecoración de su palacete:

Nada quedaba ya del salón de antes, donde reinaba el recuerdo glacial de la condesa Muffat [...] Ahora, desde la entrada, en el vestíbulo, los mosaicos realzados de oro [...] Hubiérase dicho que la 
butaca de Sabine, aquel sitial único de seda roja, cuya molicie desentonaba en otro tiempo, se había multiplicado [...] hasta llenar el palacio entero de voluptuosa pereza, de un deleite agudo, que ardía con la violencia de los fuegos tardíos (484).

Debido al cambio de imagen en sí misma y de su casa, a Sabine se la tacha de loca, estableciéndose una dualidad que "necessitates the generation of such doubles as monster characters who shadow angelic heroines" (Gilbert \& Gubar, 1979: 80). Su cualidad de ángel poco a poco va siendo cubierta por la del monstruo transgresor puesto que, como ya habíamos comentado anteriormente, Sabine evoluciona a unos extremos peligrosos para la sociedad y la institución del matrimonio. Todo se desencadena cuando Fauchery abandona a la condesa y ella se aturde "con otros amoríos en el inquieto y calenturiento arrebato de los cuarenta años" (420). Se produce entonces la gran ruptura de su imagen de dama de sociedad con el escándalo en París y su huida con el dependiente principal de un almacén de novedades debido a "un supremo arranque de locura" (539). Según resalta Francisco Caudet en la introducción -basándose a su vez en el artículo La Mosca de Oro- se rompen los contrastes y se observan los efectos devastadores en el matrimonio Muffat causados por Naná cuyo sexo era tan fuerte y su olor ${ }^{4}$ lo impregna todo (Zola, 1988: 43):

Con ella, la podredumbre que se dejaba fermentar en el pueblo, subía y corrompía la aristocracia. Venía a ser como una fuerza de la naturaleza, una levadura de destrucción, sin quererlo ella misma, corrompiendo y desorganizando a París [...] figuraba la comparación con la mosca, una mosca color de sol, remontando el vuelo desde la basura [...] envenenaba a los hombres con sólo posarse en ellos, en los palacios donde entraba por las ventanas (295).

Algunos críticos han considerado a Naná como la fuerza que, impregnándose en la vida de la alta burguesía, la degenera "spreading insidious destruction and pestilence throughout Paris" (Perry, 191: 163). Esto puede explicar la influencia de Naná en los hombres aristócratas que, como ya comentamos, pierden sus facultades cuando están a su alrededor por el erotismo con que les impregna. Sin embargo, no creo que el cambio en Sabine se deba a la influencia de Naná sino a la fuerte represión que sufre la mujer de la época:

Women are exploited and abused by men when women seek to exert power along conventionally acceptable channels. In order to seek revenge and regain some power, women must use alternate, subversive means which threaten social institutions and which weaken the traditional social fabric that has disempowered them (Slott, 1985: 98).

Tanto en el caso de Sabine como Naná, ambas tratan de enfrentarse y resistir de alguna forma el sistema opresivo que las asfixia. Incluso Naná, con toda naturalidad

\footnotetext{
${ }^{4}$ Perry apunta que en el siglo XIX, el olor se asociaba con el contagio de enfermedades, un peligro debido al contacto con las clases bajas (1991: 162).
} 
y facilidad, expone y justifica el adulterio en la mujer basándolo en la ignorancia y torpeza de los hombres. Por ejemplo, expone a Muffat sus opiniones sobre el hecho de que los hombres no tengan una experiencia sexual previa a su primera noche de casados, justificando de este modo la infidelidad de Sabine:

Cariño, el hacerse el torpe con la mujer la primera noche, suele traer malas consecuencias [...] Verás: a las mujeres no les gusta que el hombre sea torpe. No dicen nada, por aquello del pudor, ya me entiendes... Pero estáte seguro de que se forman una opinión y, antes o después, si el hombre no ha sabido arreglárselas, se buscan su apaño [...] ¿te crees que ella es de piedra? (301).

Naná es una mujer poco convencional, que no es capaz de ser fiel por propia voluntad, simplemente "por mostrarse a sí misma que era libre" (396). En cuanto a su instinto maternal, algo tan valioso en una mujer de la época, lo rechaza totalmente justamente porque también le roba su libertad sexual:

Y no salía de su sorpresa, como si sintiese que tenía trastornado el sexo: ¿o sea, que eso seguía fabricando niños, aun cuando ella ya no lo deseaba, y lo empleaba para otros menesteres? La exasperaba la naturaleza, esa maternidad grave que se alzaba en medio de su placer... ¿No hubiera sido mejor que uno pudiera disponer de sí mismo, sin tanto lío? (475).

Esta libertad sexual, que expresa a través de su cuerpo, se refleja perfectamente en la escena en la que se la describe mirándose en el espejo mientras Muffat la observa, una escena en la que Émile Zola, según Sayeeda Mamoon, impregna con tonos provocativos una sexualidad y autoerotismo perverso (Mamoon, 2001: 191): "Uno de los placeres de Naná era desnudarse delante de su armario de luna, donde se veía de cuerpo entero [...] se extasiaba mirándose largo rato. Era una pasión por su cuerpo [...] absorta en un amor hacia sí misma" (293).

Sin embargo, en el interior de Naná existe el deseo de una naturaleza temporal como sucede con todos sus impulsos, de al menos parecer una mujer honrada. En esta segunda etapa lo logra en cierta forma al convertirse en la confidente del conde Muffat, aconsejándole sobre su vida matrimonial: "Cuando llegaba malhumorado, ella le animaba, y luego le daba consejos, tras de haberle hecho confesar el porqué de ese malestar [...] la joven se ocupó de los disgustos del hogar de Muffat, de su mujer [...] mostrándose muy razonable, imbuida de justicia y honradez" (396). Naná se comporta como una buena compañera, lo que podría definirse como el ideal de esposa, e incluso aconseja a Muffat que haga las paces con su mujer para que la gente no le dé una mala fama a ella, a Naná -como si no la tuviera ya jugando de nuevo ese papel de mujer honrada: “¿Quieres que digan por todas partes que yo te he descarriado de tu hogar? Eso me daría muy mala fama" (481). En esta escena encontramos de nuevo la inversión de los personajes al parecer que Naná es la esposa y Sabine la amante: "Al fin y al cabo es tu mujer [...] No es lo mismo que si me engañaras con la primera que se te terciase" (480).

Esta segunda etapa, el momento de máxima confusión se produce durante la boda de la hija de Sabine, Estelle, con el ex amante de Naná, Daguenet. Entre los invitados a la fiesta, celebrada en el palacete redecorado al gusto de la nueva Sabine, 
se encuentran Naná, quien saluda a la condesa como cualquier otro invitado; Fauchery, el amante de Sabine; y, en resumidas cuentas, "una sociedad donde se codeaban grandes apellidos y grandes vergüenzas, en el mismo apetito de goces" (492). Es más, en esta ocasión la condesa refleja el mismo comportamiento que tuviera Naná en su primera fiesta, al no reparar en el número de invitados: "Era una locura amontonar a quinientas personas en unos salones donde apenas cabían doscientas" (492). Una situación un tanto grotesca y caótica en la que los límites se han borrado totalmente.

En la tercera fase de restablecimiento del orden, la muerte de Naná genera que vuelvan a escena las distinciones originales (Lowe, 1992: 100). Durante esta etapa, se muestra el fracaso de Sabine y Naná en su intento subversivo de borrar los límites y no dejarse definir tan fácilmente mediante los términos de ángel y demonio, algo demasiado subversivo y peligroso en una época de convenciones sociales. Al final, ambas son castigadas por este atrevimiento, aunque de forma diferente debido a sus estados y prestigio inicial en la novela. A Sabine se le da una segunda oportunidad para regresar a su condición de ángel del hogar -mostrando que es el estado ideal en la mujer- al justificar su adulterio en la figura corrosiva de Naná, con lo que se establece de nuevo la clara distinción entre el ángel y el monstruo o la fuerza diabólica: "Sabine, corrompida por la promiscuidad de esa mujer, y lanzada a todo, venía a ser el desmoronamiento final, el enmohecimiento mismo del hogar. Después de varias aventuras, había regresado, y el conde la recibió con la resignación del perdón cristiano" (539). Sin embargo, Naná no tendrá una segunda oportunidad sino que, considerada la causa de tanta degeneración, será castigada con una muerte de descomposición al tratarse "de una criatura maldita hundida en el cieno desde su origen" (540).

Como conclusión, hemos podido comprobar que los límites aparentemente tan claros entre lo que se denominaba el ángel del hogar y el monstruo, o mujer caída, en el siglo XIX, tienen una repercusión muy acentuada en las novelas de la época. Mediante el estudio de dos personajes clave en la obra de Émile Zola -Naná y Sabine- encontramos que en ocasiones no es tan fácil establecer esas delimitaciones sino que se produce una inversión de los personajes, e incluso una fusión de los mismos. En la novela Naná se podrían distinguir tres etapas: la primera de orden tradicional en la que hemos observado cómo estas delimitaciones aparecen muy claras en la novela, pudiéndose distinguir fácilmente al ángel del hogar (Sabine) frente al monstruo corrosivo (Naná), aparte de incluir algunas claves que sirven de anticipación a la siguiente fase; una segunda fase de confusión y desorden, en la que somos testigos de que en realidad esta delimitación no es tan clara y las cualidades de Sabine y Naná - tan contrastadas en la fase anterior- aparecen solapadas ya que en ocasiones Sabine nos recuerda a Naná y viceversa; una tercera fase de restablecimiento del orden en el que Sabine es perdonada y reinsertada en su papel de ángel del hogar gracias al perdón de su esposo católico y arrepentido, mientras que Naná es castigada con una muerte cruel por sus acciones transgresivas.

Bajo el punto de vista del presente estudio, la segunda fase de desorden y confusión en la novela es fundamental debido a que esta superposición de los 
personajes femeninos de Sabine y Naná muestra que la caracterización en las mujeres es más complicada que la simple distinción entre mujer virtuosa y malvada corrupta. Aunque al final se restablece el orden social, según el deseo patriarcal para salvaguardar la sociedad burguesa, al menos existe un intento de resistencia y ruptura de esas distinciones, brindando de esta forma un espacio alternativo de dualidad a la mujer de la época.

\section{REFERENCIAS BIBLIOGRÁFICAS}

Cansigno Gutiérrez, Y. \& H. Loyden, (2000) "Metamorfosis de la imagen de la mujer del siglo XIX al XX" in Durán, J. et al. (dir.), Pensamiento y crítica: los discursos de la cultura hoy. US /México, East Lansing /Centro de cultura Casa Lamm, pp. 269-88.

Gilbert, S.M \& S. Gubar, (1979) The madwoman in the attic. The woman writer and the nineteenth-century literary imagination. Londres, Yale University Press.

Jagoe, C. et al., (1988) La mujer en los discursos de género: textos y contextos en el siglo XIX. Barcelona, Icaria Editorial.

Labanyi, J., (1986) "City, country and adultery in La Regenta" in Bulletin of Hispanic studies. Vol. LXIII, $\mathrm{n}^{\circ} 1$, enero, pp. 53-65.

Lowe, R. N., (1992) "Writing the feminine in Zola" in Excavatio: Nouvelle revue Emile Zola et le naturalisme international. Vol. I, mayo, pp. 95-109.

Mamoon, S., (2001) "Mirroring femininity: specular constructions of class and gender in Zola, Manet, Morisot, and Cassat" in Excavatio: Nouvelle revue Emile Zola et le naturalisme international. Vol. XV, no 3-4, junio, pp.186-197.

Perry, K., (1991) "Containing the scent: 'Odor di femina' in Zola's Nana" in Cincinnati Romance Review. Vol. 10, pp.158-68.

Rich, L., (2001) "Fear and loathing in Vetusta: coding class and gender in Clarín's La Regenta" in Revista Canadiense de Estudios Hispánicos. Vol. 25, $\mathrm{n}^{\mathrm{0}} 3$, primavera, pp. 505-518.

Ruiz, R., (1742) Consideraciones políticas sobre conducta entre marido y muger. Madrid, Servicio de Reproducción de Libros.

Schierse Leonard, L., (1993) Meeting the madwoman. An inner challenge for feminine spirit. Nueva York, Bantam Books.

Slott, K., (1985) "Narrative tension in the representation of women in Zola's L'Assommoir and Nana" in L'Esprit Créateur. Vol. 25, $\mathrm{n}^{\circ}$ 4, pp. 93-104.

Starks, L.S., (1991) "Altar to attics: the madwoman's point of view" in Munson Deats, S. \& L. Tallent Lenker (éds.), The Aching Heart: family violence in life and literature. Nueva York, Plenum Press, pp. 105-119.

Tanner, T., (1979) Adultery in the novel. Contrast and transgression. Baltimore, The Johns Hopkins University Press.

Zola, É., (1988) Naná. Madrid, Cátedra. 